\title{
Product Network Marketing Strategy and Design Analysis ${ }^{1, a}$ Du Wei \\ ${ }^{1}$ Hainan College of Software Technology, Qionghai , Hainan 571400, China \\ a1258502015@qq.com
}

Keywords: Product Network Marketing, Strategy, 4P Marketing, Design.

\begin{abstract}
Based on 4P marketing framework, this paper analyzes current product network marketing and sets up marketing network frame diagram. We formulate network marketing strategy of one product by personalized customization, product differentiation, price strategy and separate strategy in sales-expansion strategy, and the mix of product, price and sales-expansion, the mix of price and sales-expansion, the mix of channels and other strategy profile, to improve product range and popularity and contribute to sales.
\end{abstract}

\section{Introduction}

Since formulated in 1950s, marketing has drawn many attentions because people began to realize the influence of marketing in the development and expansion of one industry. It affects an enterprise at all levels. Online digital product develops with the generation of Internet and the rapid development of e-commerce and Internet technology provide digital product with wide development and interactive mode. The ultimate goal of enterprise engaging in digital product producing and managing is to maximize profit. With the rapid expansion of netizen and flourish of shopping online, it deserves serious consideration of how domestic luxury industry including diamond jewelry can carry on network marketing to realize the organic integration from online to offline.

Based on relationship marketing theory, this paper sets up electrical network to analyze the network marketing of diamond jewelry by the five-force model. We formulate network marketing strategy based on relationship marketing by the classic 4P targeting strategy, including strategy relationship establishment, win-win partnership promotion with traditional retail store, long-tern dependence relationship with consumer, and put forwards 4P implementation plan.

\section{Construction of E-commerce Network Marketing Platform}

Considering the popularity of network marketing, FanYa determines to regard e-commerce as the sally port of marketing after a series of analytic demonstration and try to expand the traditional carrying trade to a much wider network space. Thus, the company's present e-commerce applications will undergo revolutionary strategic adjustment beyond the simple information release, which will focus on the strategic positioning of network marketing as the core in the whole market process.

Combing with traditional marketing theory and latest network marketing theory, we formulate the strategic thought with $4 \mathrm{P}$ as the core. Based on 4P, the classic evaluation model of network marketing and namely Product, Price, Place and Promotion [5] and adding the mating strategy of 4C and 4R that targeting at custom loyalty establishment and custom service oriented, strategies of FanYa moving into network marketing are formed. Those strategies are separately Product, Price, Place, Promotion, promotion strategy and service marketing strategy and organizational strategy.

The technical framework of FanYa marketing platform adopts J2EE-based MVC framework with the above consideration and its framework is as follows: 


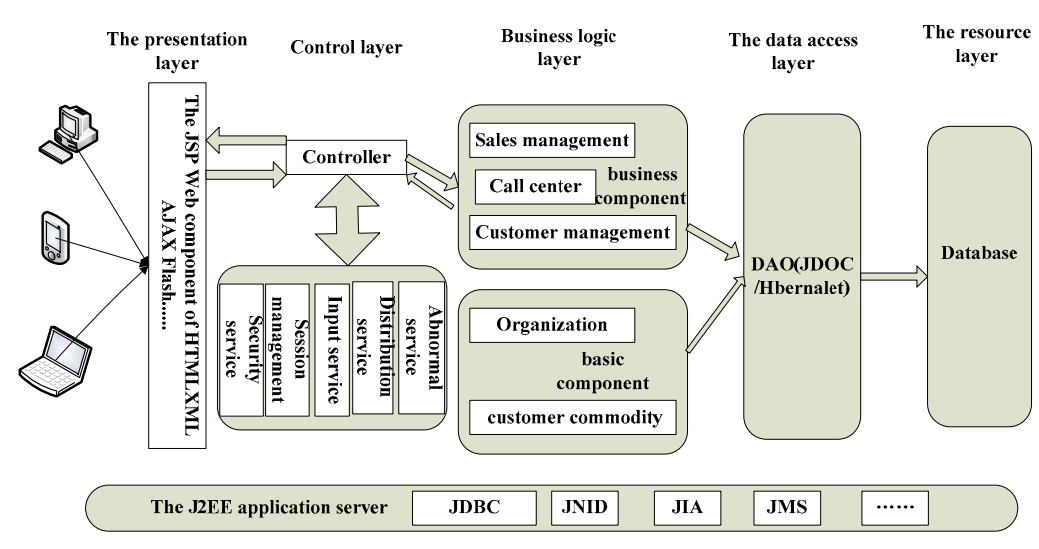

Figure 1 Product Network Marketing Framework

Reveal layer, control layer and business logic layer are deployed on application server, which adopts IBM Websphere, conforming to J2EE. Data layer is deployed on database server. System users can visit the reveal layer through the browser of PC and mobile terminal to realize the interaction with business application system.

We adopt SOA system integration framework to improve system performance, facilitate application development and promote user experience for one thing and for another it contributes to the unification of built-in system technology architecture of the company to realize the seamless communication and unified resource allocation of e-commerce and each platform. The SOA can help the company target at service and integrate the IT resources into operable standard service so as to recombine and apply. It can also enhance the flexibility of network business application to respond to market change. The network marketing platform adopts IBM WebSphere Commerce, which has various channels to integrate background business process to facilitate information exchange between the platform and the background. Interface means of the system contain Web Services, XML messaging $>$ HTTP, SMTP, non-real-time interface etc.

\section{Network Marketing Management in 4P Marketing Theory System}

4P Marketing Theory:Figure 2 shows the fundamental framework of 4P marketing. Product: Lay emphasis on the function development. It asks for the unique selling points of each product and places first the functional demands. Price: Price differently in line with different market positioning. The price basis is the brand strategy of the enterprise and gold content of the brand is valued. Place: the enterprise doesn't confront with the consumer directly. It cultivates dealers and establishes selling network. The relations of enterprise and consumer are built by dealers. Promotion: enterprise lays emphasis on motivate consumers by changing sales behaviors, for instance promoting sales increase by short-term actions (surrendering part of the profits, two for one, constructing marketing atmosphere etc.) so as to attract consumers of other brands or induce advance consumer to increase sales.

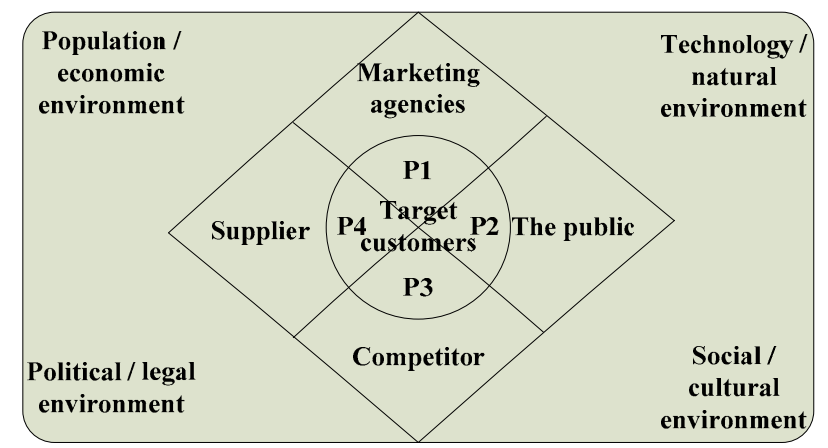

Note: P1-Product P2-Price P3-Place P4-Promotion

Figure 2 4Ps Marketing Theory Constitutional Diagram 
4P establishes the basic theoretical framework of management and marketing. This theory takes single enterprise as analysis unit and thinks there are two channels that influence marketing campaign result: one that enterprise can't control is called uncontrollable factors, such as society and environment factors like population, technology, economy, environment, politics, law, morality, geographical factors; the other is controllable factors like marketing factors like product, price, distribution, promotion etc. The essence of enterprise marketing activity is response actively to external uncontrollable factors by internal controllable factors like the planning and implement of product, price, distribution and promotion so as to facilitate transaction and meet the objection of individual and organization. In Kotler's words, if the company produces the right products, sets appropriate prices, uses appropriate distribution channels, and complements with by appropriate promotional activities, then the company will be successful. So the core of marketing is to formulate and imply effective marketing mix.

Personalized Customization: In non-digital product market, it is hard to personalize product in line with the preference of the consumers, however, it is much easier for online digital product to realize it. This is because firstly the enterprise can get access to the demand and preference of consumers to design specific digital product directing at different consumers; secondly the content of digital product can change, which make it reality to design and promote individualized digital product directly. Individualized design can pick up contents and make mix, what's more, the mix of any typeface, color, background make it unique so as to satisfy the needs of different consumers. For instance, people can purchase e-book and online music in line with personal preference.

Product Differentiation: Offer products and services suit for the consumption characteristics of various consumer group and price separately to different products and services to cover the cost. It is product granularity (the segmentation and variable of content), easy-getting consumer preference and convenient safe internet payment like E-bank, pay worm and quick money that ensure the full application of product differentiation strategy. In digital product market, manufacture divides products or services into standard edition, professional edition and gold edition separately. It is call personalized customization when a consumer is with different demand and enterprise produces formulated product or offers special service. Personalized customization is a particular case included in product differentiation. As shown in Figure 3, personalized design sparks the sight of viewers and product purchaser.

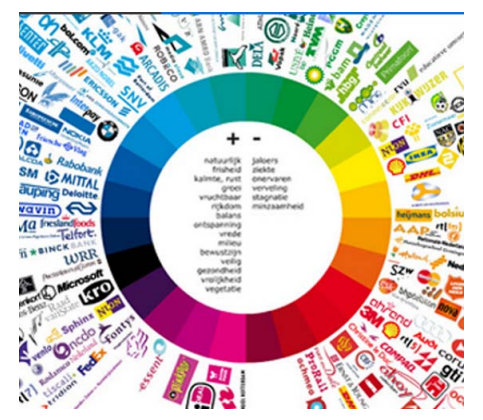

Figure 3 Individualized Designs of Multiple Products

Price Strategy:We can't interpret the supply and demand of digital product just by normal demand-and-supply curve. On the contrary, it is extremely different from traditional market, which is determined by its cost structure with marginal cost being ignored. According to economical principle, the price of digital product is approaching to zero. Thus, traditional pricing strategy can't qualify to digital product market. We should formulate new pricing strategy in line with the new characteristics: generally speaking there are mainly capturing market with low price, bundle sales, different pricing in line with various demand, cross-subsidization pricing etc. For instance, office software of Microsoft contains three procedures binding together: word, excel and ppt. we can certainly buy them separately but with much higher price than bundle sales.

Sales-expansion Strategy:In social market, buyers confront with lacking knowledge of where and in what price a certain product can be bought, but the bigger question lies in sellers failing of acquiring whole message of the buyers. To remove this conflict, sales promotion generates. 
Enterprise builds reputation by activities to create chance for consumers to know the brand and then to buy. E-commerce offers ways for promoting. Enterprise can push their products as well as get the market demand by interpreting consumer demands. Consumers don't tend to buy products needing experience, at what time the evaluation of other consumers play an important role. This kind of purchase is determined by similar successful case. Promotion strategy of free charge attracts consumption by advanced experience and feelings. Trustful brand construction should be before everything. Favorable brand image can attract potential consumers to be real consumers as well as enhance the sense of trust of the existing consumers for the support of all products. Except for advantage in quality and quantity, the advantage of online digital products lies in the individualized recognition with humanity and connotation, attracting consumers favoring individuality and brand value.

The Mix of Products and Prices:Product differentiation ensures differential pricing so as to meet the needs of different consumers and get maximum profits; at the same time, differential pricing is based on product differentiation. Targeting at the core product, value added service, low price and free of charge in pricing, bundling pricing and cross-subsidization are usually used in mix. The enterprise fights for higher market share by low price and free charge.

The Mix of Products and Sales-expansion: When issuing new product, the enterprise should conduct relevant propaganda and experience marketing according to its characteristics and advantages so that consumers needing this product can know and purchase it. After the sales, favorable quality of the product is what can ensure the sustained use. Meanwhile, cases can help to drive sales. Free and low price promotion of core product with mix of bundle sales can also drive sales. Favorable brand image establishment needs the help of propaganda and promotion and the product needs quality guarantee as well as innovation so as to sustain and expanding sales.

The Mix of Price and Sales-expansion:Pricing and sales-expansion strategy share the same characteristics in marketing and they two usually cooperate together. Many sales-expansion strategies apply price as the tool. Enterprise and dealer usually price low partly or in limited time at the initial stage after product issued to attract consumers and promote propaganda. Meanwhile, enterprise will carry on bundling sales according to bundling piecing as well so that consumer can get the benefit and the sales increases. As for personalized customization, enterprise can carry on time-limited promotions by cases to promoting sales.

The Mix of Channels and other strategies:As for channels and sales-expansion, channels are well situation for sales-expansion and direct marketing and indirect marketing also influence the way of sales-expansion. For example, direct marketing enterprise pays attention to propaganda and promotion while indirect marketing values brand preservation. As for channels and price, network direct marketing and indirect marketing varies a lot in expense with direct marketing much more expensive. However, direct marketing is much easier to control for the involving of professionals, thus pricing strategy varies a lot in channels. As for channels and sales-expansion, direct selling is easier to control so that enterprise can expand sales in multiple ways autonomously.

\section{Conclusion}

The congenital shortages of middle-sized and small enterprises lead to the lack of competition in relentless mass marketing transmission, multi-level distribution channels and cost-ignoring price war. This paper analyzes the product strategy, price strategy, channel strategy and propaganda strategy etc. to solve the marketing strategy choice online digital product confronting with in virtual and real environment. The online marketing strategy we formulated is based on relationship marketing. Online marketing strategy of a certain product can be formulated by personalized customization, product differentiation, pricing and separate strategy in sales-expansion, and the mix of product, price and sales-expansion, the mix of price and sales-expansion, the mix of channels and other strategy, which promotes product reputation and offer references to some related apartments. 


\section{Reference}

[1] Li Yuanfang. Impact of Online Jewelry Retail Brand on Traditional Jewelry Management[J]. China Brand and Anti-counterfeiting, 2010(1):76-78

[2] Wang Haibei. Luxury Marketing Management Based on Consuming Behavior Analysis[D].Beijing: Master thesis of Beijing Jiaotong University, 2010.

[3] Yang Chunli. Application Research of Online Marketing on Jewelry Industry[J]. New West, 2011(9):109-111.

[4] Yang Yanping, Li Qi. Study of Influence factors of Diamond Jewelry Online Shopping [J].Market Research, 2010(1): 38-41. .

[5] Jiang Xuping. Network Marketing[M]. Beijing: China Renmin University Press, 2011.

[6] Zhang Pengli, Wu Yuanyi. Marketing Channel Option in E-commerce [J].Market Modernization, 2008(12):139-140.

[7] Yan Jun, Jiang Yinbo, Chang Yaping. Research on the Relationship of Internet Word of Mouth Motivation and Action [J].Management Review, 2011, 23(12):84-91.

[8] Wang Zhiying. Mix Application of 4P and 4C in Enterprise Marketing[J]. CHINA MARKET.2008, (22):50-51

[9] Deng Rong, Liu Jing. Problems and Countermeasures of Online Video Marketing[J]. Forefront Observation, 2011, (1):119-121. 